\title{
Preliminary inferences on the age-specific seriousness of human disease caused by avian influenza A(H7N9) infections in China, March to April 2013
}

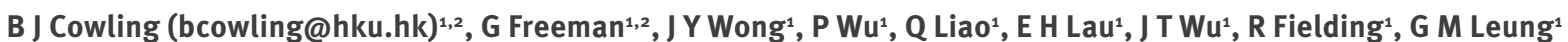

1. School of Public Health, Li Ka Shing Faculty of Medicine, The University of Hong Kong, Hong Kong Special Administrative Region, China

2. These authors contributed equally to this work

Citation style for this article:

Cowling BJ, Freeman G, Wong JY, Wu P, Liao Q, Lau EH, Wu JT, Fielding R, Leung GM. Preliminary inferences on the age-specific seriousness of human disease caused by avian influenza A(H7N9) infections in China, March to April 2013. Euro Surveill. 2013;18(19):pii=20475. Available online: http://www.eurosurveillance.org/ ViewArticle.aspx?Articleld $=20475$

Article submitted on 25 April 2013 / published on 9 May 2013

Between 31 March and 21 April 2013, 102 laboratoryconfirmed influenza $\mathrm{A}\left(\mathrm{H}_{7} \mathrm{~N} 9\right)$ infections have been reported in six provinces of China. Using survey data on age-specific rates of exposure to live poultry in China, we estimated that risk of serious illness after infection is 5.1 times higher in persons 65 years and older versus younger ages. Our results suggest that many unidentified mild influenza $\mathrm{A}\left(\mathrm{H}_{7} \mathrm{~N} 9\right)$ infections may have occurred, with a lower bound of 210-550 infections to date.

\section{Introduction}

In recent weeks, increasing numbers of avian influenza $A\left(\mathrm{H}_{7} \mathrm{~N} 9\right)$ virus infections have been identified in humans in China [1,2]. Laboratory-confirmed cases of influenza $\mathrm{A}\left(\mathrm{H}_{7} \mathrm{~N} 9\right)$ infection have typically suffered serious illness $[3,4]$, and there is a notable excess of confirmed cases in the elderly $[3,5]$. In the present analysis, we compared the incidence of serious influenza $\mathrm{A}\left(\mathrm{H}_{7} \mathrm{~N} 9\right)$ infections with data on age-specific patterns in exposure to domestic poultry and live poultry markets to estimate the relative seriousness of influenza $\mathrm{A}\left(\mathrm{H}_{7} \mathrm{~N} 9\right)$ and obtain a lower bound on the number of human infections to date.

\section{Methods}

\section{Poultry exposures in China}

We obtained unpublished data on poultry exposures in Shenzhen, a city in Guangdong province on the border with Hong Kong, and in Xiuning, a rural county in Anhui province in eastern China. In each location, a two-stage household-based cluster survey was conducted to assess poultry exposures based on average annual visits to poultry wet markets (Shenzhen, $n=2,058$ ), and ownership of backyard poultry (Xiuning, $n=2,892$ ). Trained investigators conducted each faceto-face interview with selected households, and every family member who met the inclusion criteria (aged at least five years, and resident in the study area for at least three months) was interviewed. Poultry wet markets were defined as places where small animals and poultry may be purchased alive or slaughtered just before purchase. The surveys were conducted from July to September 2007.

Data on poultry exposures in urban and semi-rural areas of Guangzhou, the capital of Guangdong province in Southern China, were obtained through face-toface interviews, from January through March 2006 [6]. Households were selected for interview through stratified cluster sampling in the ten urban districts $(n=1,363)$ and two satellite towns $(n=187)$ of Guangzhou. One adult per selected household was interviewed. We assessed household exposures to retail and domestic poultry in both urban and semi-rural locations based on average annual visits to poultry wet markets to purchase live poultry, and ownership of backyard poultry [6].

Avian influenza A(H7N9) cases Information on laboratory-confirmed human infections with influenza $A\left(\mathrm{H}_{5} \mathrm{~N}_{1}\right)$ and $\mathrm{A}\left(\mathrm{H}_{7} \mathrm{~N}_{9}\right)$ was obtained from official notifications, including age, geographic location, and seriousness of disease (mild/serious). The definition for an influenza $A\left(\mathrm{H}_{7} \mathrm{~N} 9\right)$ case is given elsewhere [3]. A serious case was defined as a laboratory-confirmed influenza $\mathrm{A}\left(\mathrm{H}_{7} \mathrm{~N} 9\right)$ case that required hospital admission for medical reasons, i.e. with a complication such as pneumonia, rather than merely for isolation. Cases defined as serious included all fatal laboratory-confirmed cases. The age-specific populations of provinces in China were obtained from the 2010 population census of the People's Republic of China [7].

\section{Statistical analysis}

We specified a model for the observed number of serious influenza $\mathrm{A}\left(\mathrm{H}_{7} \mathrm{~N} 9\right)$ infections under the assumption that the risk of infection was directly proportional to the risk of exposure, while the seriousness of infection varied by age. Specifically, we modelled $X_{i j}$, the number 
of serious influenza $\mathrm{A}\left(\mathrm{H}_{7} \mathrm{~N} 9\right)$ infections in age group $\mathrm{i}$ and area j, as following a Poisson distribution with mean $A_{i j} \times p_{i j} \times r_{i}$, where $A_{i j}$ is the population of persons in age group $\mathrm{i}(\mathrm{i}=1$ for $0-14$ years, 2 for $15-24$ years, 3 for 25-34 years, 4 for 35-44 years, 5 for 45-54 years, 6 for $55-64$ years, 7 for $\geq 65$ years) and area j (1 for Anhui-urban, 2 for Beijing-urban, 3 for Henan-rural, 4 for Jiangsu-urban, 5 for Jiangsu-rural, 6 for Shanghaiurban, 7 for Zhejiang-urban, 8 for Zhejiang-rural), $p_{i j}$ represents the incidence rate of infection by age and area over the time period covered by our analysis, and $r_{i}$ represents the age-specific risk of serious illness if infected. For urban areas $(\delta j=1)$ and rural areas $\left(\delta_{j}=0\right)$, we specified $p_{i j}=\delta_{j} \times U_{i} \times \theta_{j}+\left(1-\delta_{j}\right) \times V_{i} \times \theta_{j}$, where $U_{i}$ and $V_{i}$ represent the age-specific rates of exposure in urban and rural areas, respectively, while $\theta_{j}$ represents the area-specific risk of infection. In our main analysis, we modelled the risk of serious illness conditional on infection as $r_{i}$ taking value $r_{\text {old }}$ for age $\geq 65$ years and $r_{\text {young }}$ for age 65 years. We explored other parameterisations for $r i$ such as $r_{i}=r_{7} \times \exp (\beta \times(i-7))$ in sensitivity analyses.
We used a Bayesian inferential framework to fit the model to observed data on $X_{i j}, A_{i j}$ and $\delta_{j}$, incorporating $U_{i j}$, and $V_{i j}$ as parameters with strong prior distributions from the survey data to retain uncertainty (as is standard in Bayesian evidence synthesis [8]), and $r_{\text {old }}$ as a parameter with a strong prior based on observed mild and serious influenza $\mathrm{A}\left(\mathrm{H}_{7} \mathrm{~N} 9\right)$ cases. We estimated $\theta_{j}$ and $r_{\text {young }}$ using independent uninformative uniform priors on the positive real line for each $\theta_{j}$ and on the $(0,1)$ interval for $r_{\text {young. }}$. Models were fitted with the Hamiltonian Monte Carlo sampler NUTS [9] using the Stan modelling language in $R$ version 3.0.0 ( $R$ Foundation for Statistical Computing, Vienna, Austria). Convergence of the simulations was assessed using the potential scale reduction statistic [10].

After fitting the models, posterior estimates of the model parameters were used to estimate $q_{i j}=A_{i j} \times p_{i j}$ as the total number of influenza $\mathrm{A}\left(\mathrm{H}_{7} \mathrm{~N} 9\right)$ infections for each age group $i$ and area $j$. This estimate can be

\section{FIGURE 1}

Geographical location of officially announced serious cases of influenza A(H7N9) virus infection in mainland China, 31 March-21 April 2013 ( $\mathrm{n}=98)$

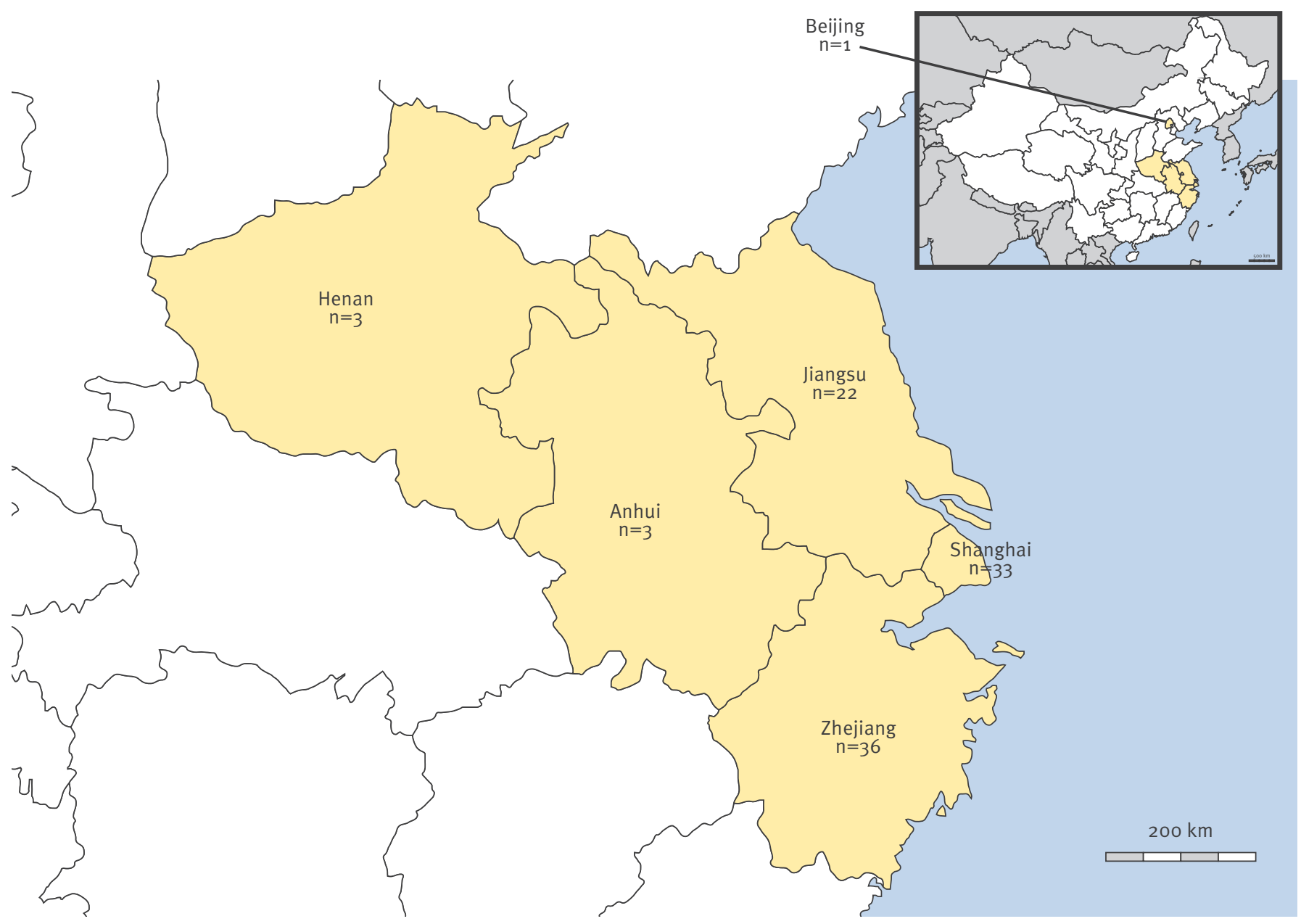




\section{FIGURE 2}

Age distribution of laboratory-confirmed human infections with avian influenza A(H5N1) in 2003-2013 (n=43) and A(H7N9) notified between 31 March 2013 through 21 April 2013 (n=102), mainland China

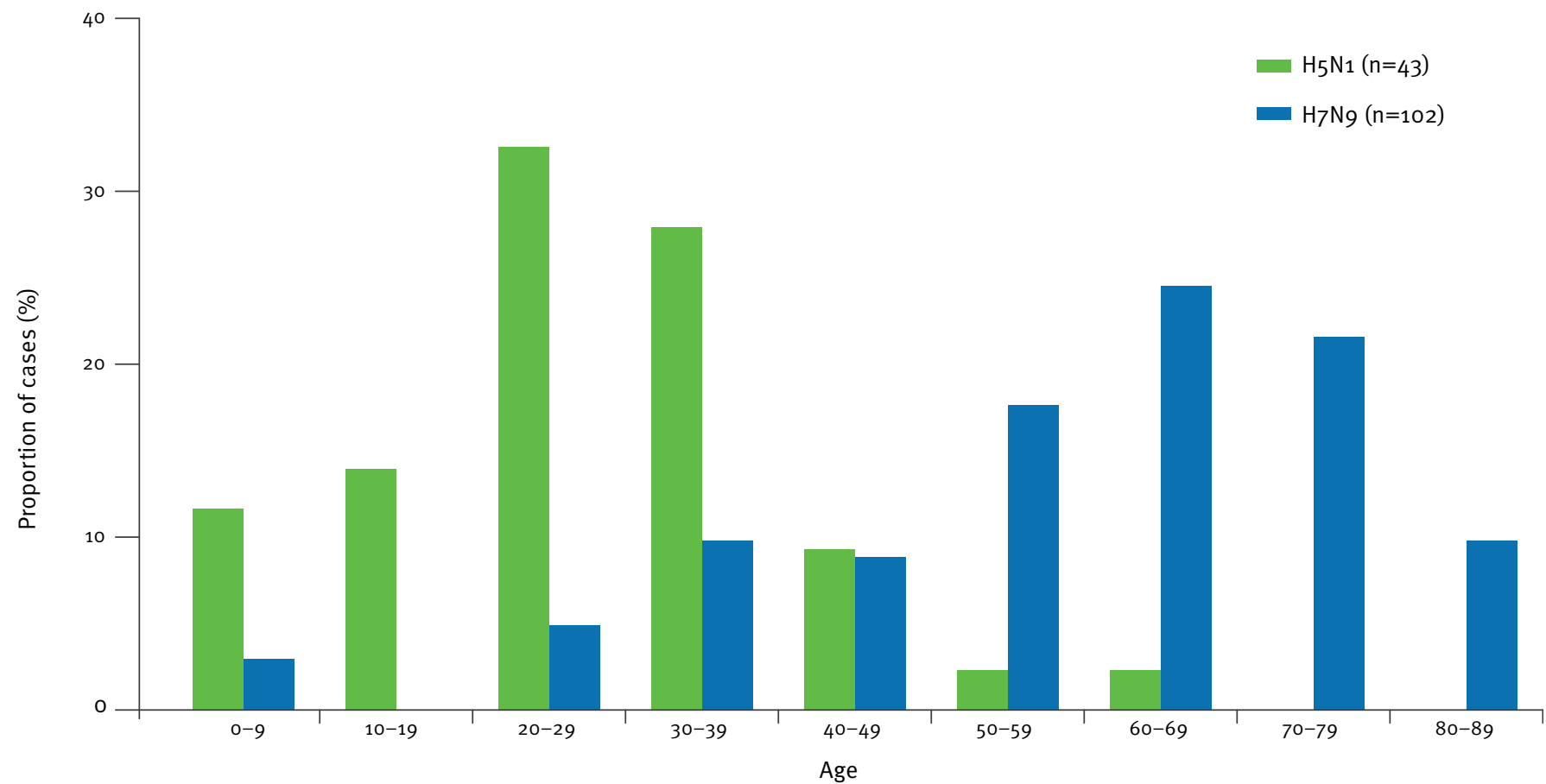

\section{TABLE}

Serious influenza $\mathrm{A}(\mathrm{H} 7 \mathrm{~N} 9)$ cases reported in six provinces of mainland China, and corresponding population denominators, 31 March-21 April $2013(\mathrm{n}=98)^{\mathrm{a}}$

\begin{tabular}{|c|c|c|c|c|c|c|c|}
\hline \multirow[t]{2}{*}{ Province-type } & \multicolumn{7}{|c|}{ Age group (years) } \\
\hline & $0-14$ & $15-24$ & $25-34$ & $35-44$ & $45-54$ & $55-64$ & $\geq 65$ \\
\hline \multicolumn{8}{|c|}{ Number of serious influenza $\mathrm{A}\left(\mathrm{H}_{7} \mathrm{~N} 9\right)$ cases } \\
\hline Anhui-urban & 0 & 0 & 0 & 1 & 0 & 2 & 0 \\
\hline Beijing-urban & 1 & 0 & 0 & 0 & 0 & 0 & 0 \\
\hline Henan-rural & 0 & 0 & 1 & 1 & 0 & 0 & 1 \\
\hline Jiangsu-urban & 0 & 1 & 3 & 1 & 3 & 4 & 6 \\
\hline Jiangsu-rural & 0 & 0 & 1 & 0 & 1 & 0 & 2 \\
\hline Shanghai-urban & 2 & 0 & 1 & 1 & 5 & 5 & 19 \\
\hline Zhejiang-urban & 0 & 0 & 0 & 5 & 2 & 6 & 11 \\
\hline Zhejiang-rural & 0 & 0 & 0 & 1 & 1 & 3 & 7 \\
\hline \multicolumn{8}{|l|}{ Population size } \\
\hline Anhui-urban & $1,617,392$ & $2,299,994$ & $1,965,849$ & $2,512,466$ & $1,671,583$ & $1,135,834$ & 979,469 \\
\hline Beijing-urban & $1,311,411$ & $2,968,261$ & $3,513,686$ & $2,657,513$ & $2,278,771$ & $1,485,603$ & $1,347,970$ \\
\hline Henan-rural & $13,341,020$ & $9,674,352$ & $6,711,837$ & $9,040,458$ & $7,264,034$ & $6,516,703$ & $5,261,768$ \\
\hline Jiangsu-urban & $3,390,036$ & $6,004,427$ & $5,389,879$ & $5,658,879$ & $4,150,560$ & $3,042,830$ & $2,529,855$ \\
\hline Jiangsu-rural & $4,421,789$ & $4,517,515$ & $3,459,924$ & $5,406,568$ & $4,789,994$ & $4,443,849$ & $4,249,814$ \\
\hline Shanghai-urban & $1,483,687$ & $2,821,598$ & $3,660,496$ & $2,797,231$ & $2,809,896$ & $2,267,794$ & $1,800,140$ \\
\hline Zhejiang-urban & $2,449,320$ & $4,004,494$ & $4,044,383$ & $4,062,503$ & $2,768,791$ & $1,707,271$ & $1,349,532$ \\
\hline Zhejiang-rural & $2,888,769$ & $2,448,074$ & $2,676,907$ & $3,835,297$ & $3,477,935$ & $2,840,965$ & $2,708,735$ \\
\hline
\end{tabular}

a The four mild cases among the total of 102 cases are not shown in this Table.

b Population sizes obtained from the 2010 population census of the People's Republic of China, published on the official website of National Bureau of Statistics of China [7]. 


\section{FIGURE 3}

Comparison of age-specific cumulative incidence of serious illness associated with laboratory-confirmed influenza A(H7N9) virus infection, 31 March-21 April 2013, and age-specific poultry exposures, 2006 and 2007, China

A

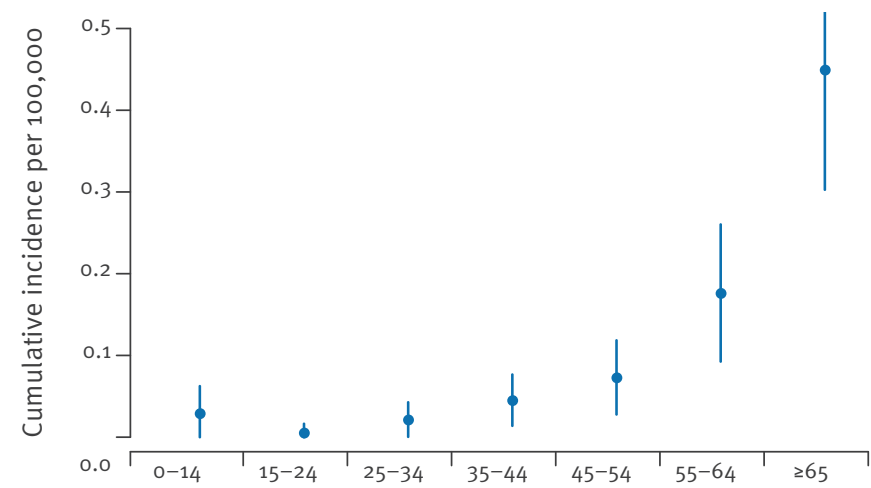

C

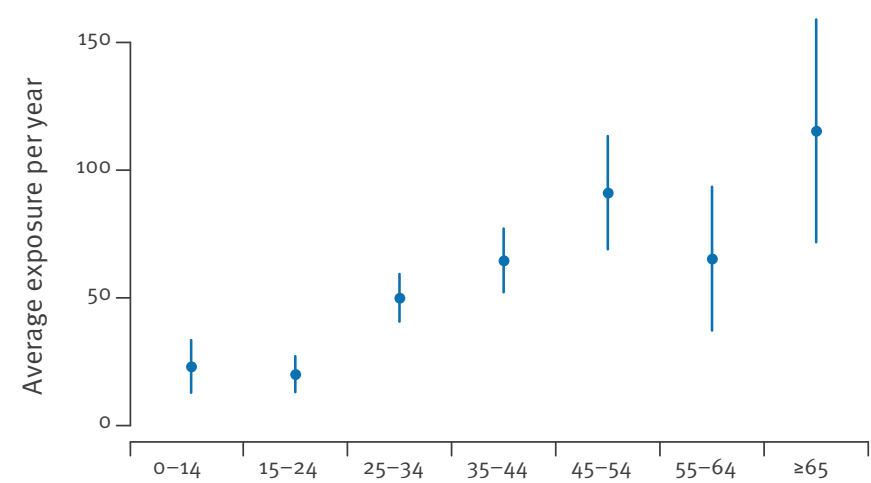

$E$

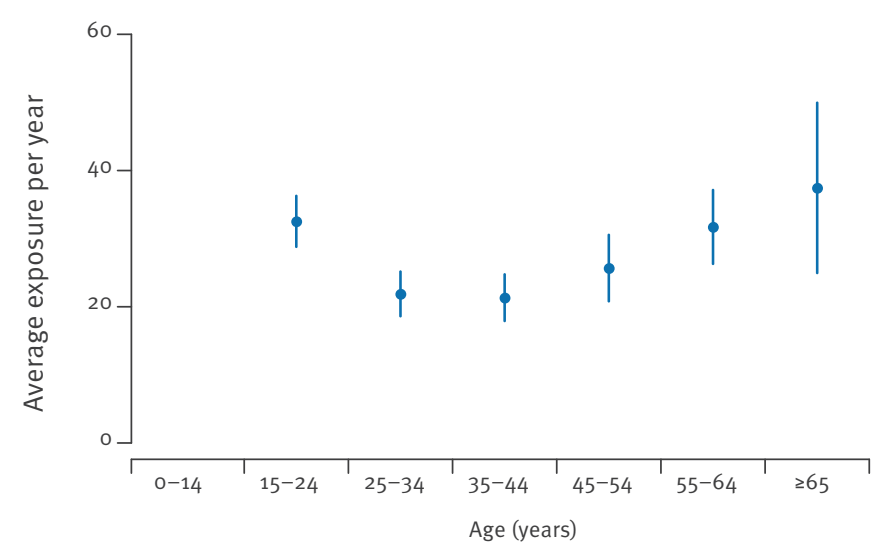

B Rural

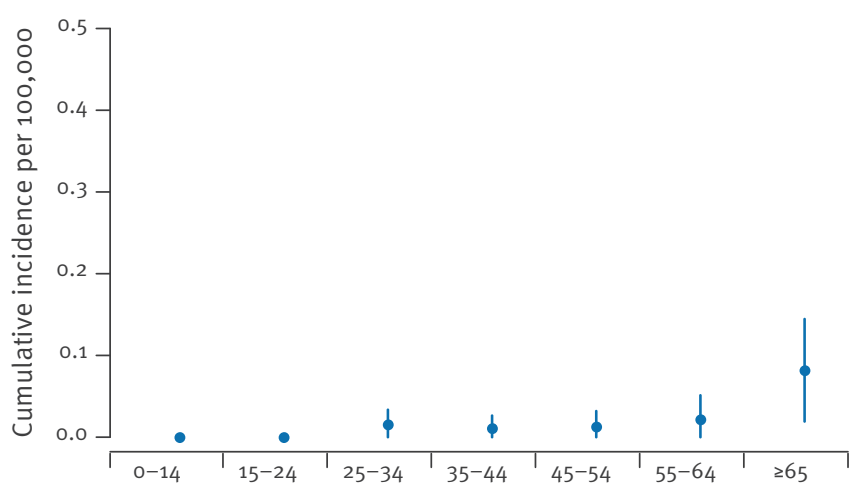

D

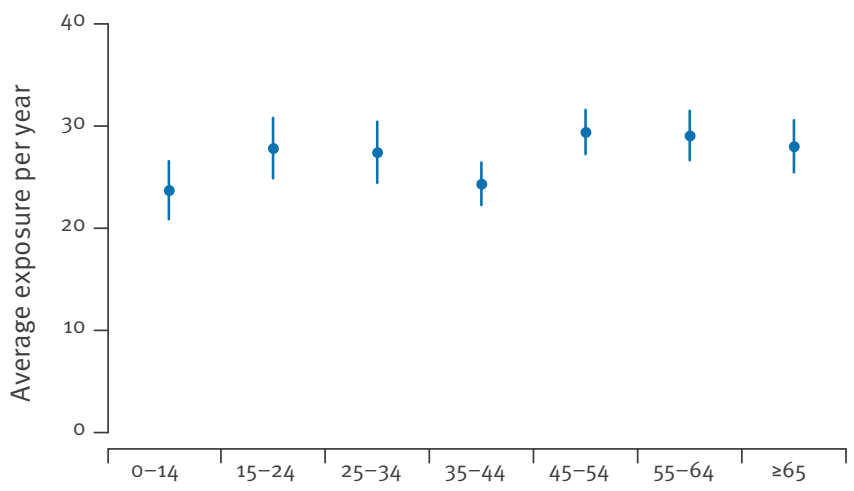

$\mathrm{F}$

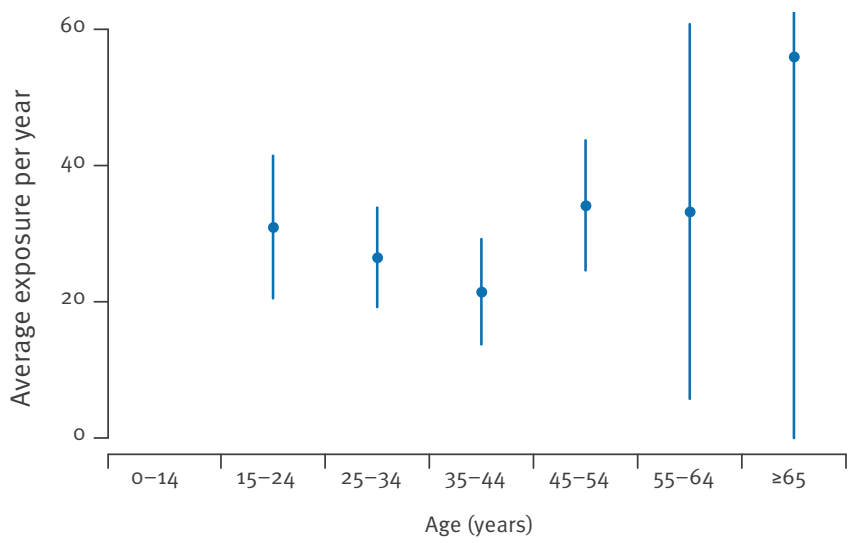

Panels $A$ and $B$ show cumulative incidence and $95 \%$ confidence intervals of serious influenza $A\left(\mathrm{H}_{7} \mathrm{Ng}\right)$ cases in $(A)$ urban and $(B)$ rural populations, based on 98 serious cases reported by 21 April 2013 . Panels $C$ to $F$ show rates of exposures to retail and domestic poultry in (C) urban Shenzhen in 2007, (D) rural Xiuning in 2007, (E) urban Guangzhou in 2006, and (F) semi-rural Guangzhou in 2006. 
regarded as a lower bound on the number of influenza $\mathrm{A}(\mathrm{H} 7 \mathrm{~N} 9)$ infections because it relies on complete ascertainment of all serious influenza $A\left(\mathrm{H}_{7} \mathrm{~N} 9\right)$ cases, and complete ascertainment of all influenza $A\left(\mathrm{H}_{7} \mathrm{Ng}\right)$ infections in people aged 65 years and older. We also estimated $\beta_{\text {age }}=r_{\text {old }} / r_{\text {young }}$, the relative risk of serious illness conditional on infection in those aged 65 years and older compared with those younger than 65 years.

\section{Results}

Between 31 March and 21 April 2013, 102 laboratoryconfirmed human influenza $\mathrm{A}(\mathrm{H} 7 \mathrm{Ng})$ cases were officially announced in six provinces of China. The affected areas were the cities and provinces around the city of Shanghai on the eastern coast of mainland China (Figure 1).

The age distribution of influenza $A\left(\mathrm{H}_{7} \mathrm{~N} 9\right)$ cases was very different to the age distribution of the 43 influenza $\mathrm{A}\left(\mathrm{H}_{5} \mathrm{~N}_{1}\right)$ cases reported between 2003 and 2013 in mainland China (Figure 2). In particular, $56 \%$ of the influenza $\mathrm{A}\left(\mathrm{H}_{7} \mathrm{~N} 9\right)$ cases were persons aged 60 years or older, whereas the majority of influenza $A\left(\mathrm{H}_{5} \mathrm{~N}_{1}\right)$ cases were young adults aged 20 to 39 years. In the eight affected areas, there were a total of 98 serious influenza $\mathrm{A}(\mathrm{H} 7 \mathrm{Ng})$ cases in a total population of 206 million persons (Table). The cumulative number of serious influenza $A\left(\mathrm{H}_{7} \mathrm{~N} 9\right)$ cases increased substantially with age particularly in urban locations (Figure 3).

We fitted the model described above to data on the incidence rates of serious influenza $A\left(\mathrm{H}_{7} \mathrm{~N} 9\right)$ cases in the six provinces, along with poultry exposures in urban and rural locations (Figure 2). In the age group of at least 65 years there were 46 serious and one mild infection, so we used a beta $(47,2)$ distribution for the parameter $r_{\text {old }}$.

Based on the exposure data from Shenzhen and Xiuning to reflect exposures in affected urban and rural areas, we obtained the estimate $\beta_{\text {age }}=5.06$ ( $95 \%$ credibility interval (Cl): 2.99-8.15), corresponding to a 5.06 -fold increase in the risk of serious illness for those aged 65 years and older versus those younger than 65 years. The estimated values of $p_{i j}$ and the observed values of $A_{i j}$ were then used to estimate that there have been at least 323 (95\% Cl: 214-475) total influenza $\mathrm{A}(\mathrm{H} 7 \mathrm{Ng})$ infections in the population, including those reported. When we used the exposure data from Guangzhou to reflect exposures in affected urban and rural areas, we estimated $\beta_{\text {age }}=5.95$ ( $95 \% \mathrm{Cl}: 3.37-10.00$ ), and an estimated minimum number of 352 ( $95 \% \mathrm{Cl}$ : 225-541) total influenza $A\left(\mathrm{H}_{7} \mathrm{~N} 9\right)$ infections in adults (because we did not have exposure data for children in Guangzhou).

In sensitivity analyses, results were similar using alternative simple parameterisations for the effect of age. For example when we used $r_{i}=r_{7} \times \exp (\beta \times(i-7))$, we obtained an estimated 1.83 -fold ( $95 \% \mathrm{Cl}$ : $1.56-2.18$ ) increase in the risk of serious illness for every ten-year increase in age, and an estimate of at least 334 (95\% $\mathrm{Cl}$ : 239-461) total influenza $\mathrm{A}\left(\mathrm{H}_{7} \mathrm{Ng}\right)$ infections in the population. The small sample size did not allow us to examine more complex functional forms for $r_{i}$. All analyses reported above were based on data available until April 25; we repeated the analyses based on data available until May 6 and the relationship between age and seriousness of disease was essentially the same.

\section{Discussion}

Our results suggest that the seriousness of influenza $\mathrm{A}\left(\mathrm{H}_{7} \mathrm{~N} 9\right)$ infections increases with age. Previous reports also identified increases with older age in the seriousness of seasonal influenza [11] and H1N1pdmog $[12,13]$, although this may partly be due to the role of secondary bacterial pneumonia, whereas many of the influenza $\mathrm{A}\left(\mathrm{H}_{7} \mathrm{~N} 9\right)$ deaths have been associated with primary viral pneumonia [4]. However, the age distribution of serious human infections with avian influenza $A\left(\mathrm{H}_{5} \mathrm{~N}_{1}\right)$ is very different (Figure 1 ). The patterns of exposure to avian influenza $A\left(\mathrm{H}_{5} \mathrm{~N}_{1}\right)$ and $A\left(\mathrm{H}_{7} \mathrm{~N}_{9}\right)$ viruses by age may not be identical because of the high degree of pathogenicity of influenza $\mathrm{A}\left(\mathrm{H}_{5} \mathrm{~N}_{1}\right)$ in poultry compared with the absence of disease in poultry with influenza $A\left(\mathrm{H}_{7} \mathrm{~N}\right.$ ) infections [4], at least before to the national influenza $A\left(\mathrm{H}_{5} \mathrm{~N}_{1}\right)$ vaccination programme in poultry was introduced in 2006-07. Exposures to sick or dead poultry would be more frequent in farms and backyards, compared to live poultry markets. In addition, healthcare seeking behaviours may also have changed over the past 10 years. There are various potential explanations for an increased risk of serious illness for influenza $A\left(\mathrm{H}_{5} \mathrm{~N}_{1}\right)$ infections in young adults compared to other ages, and these hypotheses deserve further investigation [14].

We estimated that a minimum of $210-550$ influenza $\mathrm{A}\left(\mathrm{H}_{7} \mathrm{~N} 9\right)$ infections have occurred by 21 April 2013, assuming that almost all influenza $A\left(\mathrm{H}_{7} \mathrm{~N} 9\right)$ infections are serious in the elderly and that all serious infections have been identified. This estimate is therefore a lower bound on the number of total influenza $A\left(\mathrm{H}_{7} \mathrm{~N} 9\right)$ infections, and for these two reasons the real figure may be substantially higher. There could be some underascertainment of serious influenza $A\left(\mathrm{H}_{7} \mathrm{~N} 9\right)$ infections through failure to seek care or failure to be tested early enough in the course of disease to permit identification of the influenza infection [5]. Our estimate is also dependent on the assumption that age-specific patterns of exposure to retail and domestic poultry in affected areas of China in 2011 are similar to the patterns measured in Guangzhou, Shenzhen and Xiuning in 2006 and 2007. We are not aware of data on agespecific patterns in poultry exposures from eastern China other than our unpublished data from Xiuning, and future collection of such data from across China (and across South-east Asia) in urban and rural settings would be extremely useful.

Our estimates are limited by the lack of data on exposures in affected urban and rural areas. In particular, the higher risk for infection in males compared to females could be due to variation in sex-specific rates 
of exposure by region [5]. Without data on such differences, we did not include sex in our models. Most confirmed cases report exposure to live poultry [3] and this remains the most likely source of infection for the majority of influenza $\mathrm{A}\left(\mathrm{H}_{7} \mathrm{Ng}\right)$ cases. However, the exposure distributions used in our analysis may not fully capture the age-specific risk profile, if there are other sources of infection apart from retail and domestic poultry. As of April 25, we are not aware of provinces in China with laboratory-confirmed $\mathrm{A}\left(\mathrm{H}_{7} \mathrm{Ng}\right)$ cases in poultry but not in humans. Finally, no published information is available on population levels of immunity to influenza $\mathrm{A}\left(\mathrm{H}_{7} \mathrm{~N} 9\right)$, although preliminary investigations suggest very low antibody levels against influenza $A\left(\mathrm{H}_{7} \mathrm{~N} 9\right)$ virus in all ages, and we assumed there was no heterogeneity in immunity by age. If older persons had some degree of immunity against influenza $A\left(\mathrm{H}_{7} \mathrm{~N} 9\right)$ through potential past exposures to avian influenza viruses, this would imply an even higher number of undetected infections in adults based on our method.

In conclusion, we estimated a lower bound for the number of influenza $A\left(\mathrm{H}_{7} \mathrm{~N}\right.$ 9) infections based on the possible age distribution of exposures and varying seriousness of infection by age. More accurate estimates of the risk of influenza $A\left(\mathrm{H}_{7} \mathrm{~N} 9\right)$ infection and the age-specific seriousness of infection could be provided by detailed seroepidemiological studies in affected areas [15].

\section{Acknowledgements}

We thank Vicky Fang, Angel Li, Michael Ni and Hoi Wa Wong for technical assistance.

This research was supported by the Harvard Center for Communicable Disease Dynamics from the National Institute of General Medical Sciences (grant no. U54 GMo88558), the Research Fund for the Control of Infectious Disease, Food and Health Bureau, Government of the Hong Kong Special Administrative Region, and the Area of Excellence Scheme of the Hong Kong University Grants Committee (grant no. AoE/M-12/06). The funding bodies had no role in study design, data collection and analysis, preparation of the manuscript, or the decision to publish.

\section{Potential conflicts of interest}

BJC reports receipt of research funding from Medlmmune Inc., and consults for Crucell NV. GML has received speaker honoraria from HSBC and CLSA. The authors report no other potential conflicts of interest.

\section{Authors' contributions}

Designed the study: BJC. Collected, synthesised and analysed data: BJC, GF, JYW, PW, QL, RF. Wrote the first draft: $B J C$. Interpreted the results and revised the article: GF, JYW, QL, PW, JTW, EHYL, RF, GML. All authors read and approved the final manuscript.

\section{References}

1. Gao R, Cao B, Hu Y, Feng Z, Wang D, Hu W, et al. Human infection with a novel avian-origin influenza $A\left(\mathrm{H}_{7} \mathrm{~N} 9\right)$ virus. $\mathrm{N}$ Engl J Med. 2013;Apr 11. [Epub ahead of print]. http://dx.doi. org/10.1056/NEJMoa1304459

2. Uyeki TM, Cox NJ. Global Concerns Regarding Novel Influenza A (H7Ng) Virus Infections. N Engl J Med. 2013;Apr 11. [Epub ahead of print]. http://dx.doi.org/10.1056/NEJMp1304661

3. Li Q, Zhou L, Zhou M, Chen Z, Li F, Wu H, et al. Preliminary report: epidemiology of the avian influenza $A\left(\mathrm{H}_{7} \mathrm{Ng}\right)$ outbreak in China. N Engl J Med. 2013;Apr 24. [Epub ahead of print]. http://dx.doi.org/10.1056/NEJMoa1304617

4. Chen Y, Liang W, Yang S, Wu N, Gao H, Sheng J, et al. Human infections with the emerging avian influenza $\mathrm{A} \mathrm{H} \mathrm{H}^{\mathrm{N}} 9$ virus from wet market poultry: clinical analysis and characterisation of viral genome. Lancet. 2013;Apr 25. pii: So140-6736(13)609034. http://dx.doi.org/10.1016/S0140-6736(13)60903-4

5. Arima Y, Zu R, Murhekar M, Vong S, Shimadaa T, World Health Organization Regional Office for the Western Pacific Event Management Team. Human infections with avian influenza $\mathrm{A}(\mathrm{H} 7 \mathrm{Ng})$ virus in China: preliminary assessments of the age and sex distribution. Western Pac Surveill Response J. 2013;4(2). doi:10.5365/wpsar.2013.4.2.005.

6. Liao $Q$, Lam WW, Jiang CQ, Ho EY, Liu YM, Zhang WS, et al. Avian influenza risk perception and live poultry purchase in Guangzhou, China, 2006. Risk Anal 2009; 29:416-24. http:// $\mathrm{dx}$.doi.org/10.1111/j.1539-6924.2008.01157.x

7. National Bureau of Statistics of China. Tabulation of the 2010 population census of the People's Republic of China. Beijing: National Bureau of Statistics of China. [Accessed 25 April 2013]. Available from: http://www.stats.gov.cn/english/ statisticaldata/censusdata/rkpc2010/indexch.htm

8. Presanis AM, De Angelis D, New York City Swine Flu Investigation Team, Hagy A, Reed C, Riley S, et al. The severity of pandemic $\mathrm{H}_{1} \mathrm{~N}_{1}$ influenza in the United States, from April to July 2009: a Bayesian analysis. PLoS Med. 2009; 6(12):e1000207. http://dx.doi.org/10.1371/journal. pmed.1000207

9. Hoffman MD, Gelman A. The no-U-turn sampler: adaptively setting path lengths in hamiltonian monte carlo. arXiv:1111.4246v1 [stat.CO]. 18 Nov 2011.

10. Gelman A, Rubin DB. Inference from iterative simulation using multiple sequence. Statist Sci. 1992;7(4):457-72. http://dx.doi. org/10.1214/ss/1177011136

11. Simonsen L, Fukuda K, Schonberger LB, Cox NJ. The impact of influenza epidemics on hospitalizations. J Infect Dis. 2000;181(3):831-7. http://dx.doi.org/10.1086/315320. PMid:10720501

12. Van Kerkhove MD, Vandemaele KA, Shinde V, JaramilloGutierrez G, Koukounari A, Donnelly CA, et al. Risk factors for severe outcomes following 2009 influenza $A\left(\mathrm{H}_{1} \mathrm{~N}_{1}\right)$ infection: a global pooled analysis. PLoS Med. 2011;8(7):e1001053. http:// dx.doi.org/10.1371/journal.pmed.1001053 PMid:21750667 PMCid:3130021

13. Wong JY, Wu P, Nishiura H, Goldstein E, Lau EH, Yang L, et al. Infection Fatality Risk of the Pandemic $\mathrm{A}\left(\mathrm{H}_{1} \mathrm{~N}_{1}\right) 2009$ Virus in Hong Kong. Am J Epidemiol. 2013;177(8):834-40. http://dx.doi. org/10.1093/aje/kws314

14. Liem NT, Tung CV, Hien ND, Hien TT, Chau NQ, Long HT, et al. Clinical features of human influenza $\mathrm{A}\left(\mathrm{H}_{5} \mathrm{~N}_{1}\right)$ infection in Vietnam: 2004-2006. Clin Infect Dis. 2009;48(12):1639-46. http://dx.doi.org/10.1086/599031

15. Van Kerkhove MD, Broberg E, Engelhardt OG, Wood J, Nicoll A, CONSISE steering committee. The consortium for the standardization of influenza seroepidemiology (CONSISE): a global partnership to standardize influenza seroepidemiology and develop influenza investigation protocols to inform public health policy. Influenza Other Respi Viruses. 2013;7(3):231-4. http://dx.doi.org/10.1111/irv.12068 